\title{
O PAPEL DA MULHER NA CIÊNCIA: O CONHECIMENTO PEDAGÓGICO DO CONTEÚDO DE UMA FUTURA PROFESSORA DE CIÊNCIAS MOBILIZADO NA CONSTRUÇÃO DE UMA SEQUÊNCIA DIDÁTICA
}

\author{
THE ROLE OF WOMEN IN SCIENCE: THE FUTURE SCIENCE TEACHER' \\ PEDAGOGICAL CONTENT KNOWLEDGE MOBILIZED IN THE \\ CONSTRUCTION OF A DIDACTIC SEQUENCE
}

\author{
Boniek Venceslau da Cruz Silva ${ }^{1}$ \\ ORCID iD: $\underline{0000-0002-1648-2652}$
}

\begin{abstract}
RESUMO
Questões relacionadas ao como ensinar temas sobre a Ciência são recorrentes no campo da Didática das Ciências. Estas questões perpassam no como os professores de Ciências pensam e elaboram estratégias didáticas com esse objetivo. Nesse estudo, apresentamos como uma futura professora de Ciências mobiliza seu conhecimento pedagógico do conteúdo para tal finalidade e, em especial, na discussão do papel da mulher na Ciência. A partir da construção de uma sequência didática, com estes fins, e na resolução de um questionário específico para acessar o conhecimento pedagógico do conteúdo; podemos mostrar que alguns conhecimentos são potencializados na tarefa e outros se mostraram deficitários, como, por exemplo, os relacionados às estratégias didáticas e a avaliação, respectivamente. Por fim, mais atividades que busquem potencializar a mobilização do conhecimento pedagógico do conteúdo dos professores, principalmente na produção de atividades com o intuito de ensinar temas sobre a Ciência, devem ser pensadas e discutidas nos cursos de formação de professores.
\end{abstract}

Palavras-chave: Ensino de Ciências. Natureza da Ciência. Conhecimento Pedagógico do Conteúdo.

\begin{abstract}
Questions about how to teach themes about Science are recurrent in the field of Science Didactics. These questions say respect about how science teachers think and develop didactic strategies for that purpose. In this research, we present how a future science teacher mobilizes her pedagogical content knowledge for this purpose and, in particular, in the discussion of the role of women in science. From the construction of a didactic sequence and the resolution of a specific questionnaire to access the pedagogical content knowledge; we can show that some knowledge is upgrade in the activite, but others knowledge show deficits, for example, those related to teaching strategies and assessment, respectively. Finally, more activities that seek to upgrade the mobilization of the teachers' pedagogical content knowledge, especially in the production of activities with the aim of teaching themes about Science, should be considered and discussed in teacher training courses.
\end{abstract}

Keywords: Science Education. Nature of Science. Pedagogical Content Knowledge.

\footnotetext{
${ }^{1}$ Doutor em Ensino de Ciências e Matemática (UFRN). Professor da Universidade Federal do Piauí (UFPI), Teresina, Piauí, Brasil. Endereço para correspondência: Residencial Jardim do Leste, Quadra I, casa 15, Verde Lar, Teresina, Piauí, CEP: 64037-780. E-mail: boniek@ufpi.edu.br.
} 


\section{INTRODUÇÃO}

Shulman (1986; 1987) estabeleceu algumas questões que norteiam, até hoje, uma parte dos pesquisadores no campo da Educação, de forma geral, e do Ensino de Ciências, de forma específica; são elas: Como o futuro-professor, ao se tornar professor iniciante, transforma o conhecimento que ele possui em conhecimentos compreensíveis para os alunos da educação básica? Como o professor transforma o seu entendimento do livro didático em conhecimento ensinável para os seus estudantes?

Conforme Gess-Newsome (1999), o que realmente estava em jogo, desde meados da década de oitenta do século passado, era entender o que influenciava no processo de construção/desenvolvimento do conhecimento dos professores e como estes conhecimentos eram transformados em conhecimento ensinável para os estudantes da educação básica. Para a autora, em 1986, um novo modelo foi proposto com possibilidades de clarear as dúvidas neste campo. Para ela, a proposta de Shulman era compreender o entendimento cognitivo dos professores sobre os conteúdos específicos e suas relações entre os conhecimentos pedagógicos que os professores já detinham, devido suas experiências formativas ou no exercício de suas profissões.

Desse modo, no seu artigo Those Who understand: knowledge growth in teaching, Shulman (1986) aponta a existência de três categorias relativas ao conhecimento para os professores: Conhecimento do conteúdo específico, Conhecimento do currículo e Conhecimento pedagógico para o conteúdo. Já no seu artigo Knowledge and teaching: foundations of the new reform, Shulman (1987) apresenta sete conhecimentos necessários para o professor. São eles: 1. Conhecimento de Conteúdo; 2. Conhecimento Pedagógico Geral; 3. Conhecimento Pedagógico do Conteúdo; 4. Conhecimento dos Aprendizes; 5. Conhecimento Curricular; 6. Conhecimento dos Contextos Educacionais e 7. Conhecimento dos Fins Educacionais.

O modelo de explicação descrito por Gess-Newsome (1999), que seria a peça que restava para o jogo, foi chamada, por Lee Shulman, de Pedagogical Content Knowledge (PCK, em inglês, e traduzido como conhecimento pedagógico do conteúdo). Para Shulman, o PCK seria o amálgama entra o conteúdo e a pedagogia. Como destaca Kind (2009), desde a proposição de Shulman até os dias atuais, o PCK é alvo de intensas pesquisas, que buscam definir a sua conceituação, natureza e construção de modelos explicativos para as mais variadas disciplinas e conteúdos, sejam científicos ou metacientíficos. 
Assim, não é incomum encontrarmos várias definições para o PCK, por exemplo, Magnusson, Krajcik e Borko (1999) definem o PCK como a transformação de vários conhecimentos para ensinar. Ele representa o domínio efetivo do professor. Ele engloba conhecimento particular dos tópicos, problemas, de como os métodos de ensino podem ser organizados, representados e adaptados para diversos interesses de aprendizagens e de como são apresentados para a sua instrução.

Kind (2009), o PCK traduz os conhecimentos que afloram no professor durante o processo de ensino, ou seja, ele toma corpo no momento que o futuro professor ou professor experiente planeja sua aula, no material que ele escolhe para o planejamento e em como ele o utiliza na aula, no momento da avaliação de seus estudantes, dentre outros.

Atualmente, como podemos notar nas investigações de Silva e Martins (2018; 2019), o PCK também vem servindo para compreender como os professores de Ciências mobilizam e desenvolvem seus PCK em relação a diferentes temas sobre a Natureza da Ciência (NdC). Estudos similares também podem ser vistos nos trabalhos de Demirdogen e UzuntiryakiKondakçl (2016); Hanuscin, Lee e Akerson (2010); Schwartz e Lederman (2002); Silva e Martins (2019), que buscam respostas para o que seria o PCK sobre a Natureza da Ciência (PCK/NdC), sua natureza e modelos de $\mathrm{PCK} / \mathrm{NdC}^{2}$.

Silva e Martins (2019) ressaltam que o PCK/NdC surge da transformação de diferentes conhecimentos da base para o ensino de conteúdos metacientíficos que o professor possui. Sendo possível o desenvolvimento destes conhecimentos da base, inclusive o PCK/NdC, a partir da reflexão de experiências formativas que os futuros professores de Física participam nos cursos de formação. Dando ao PCK/NdC uma característica evolutiva e não estática.

Ainda, Silva e Martins (2018; 2019) apresentam um modelo de PCK/NdC que pode apresentar potencialidades de avaliação da mobilização do PCK/NdC de professores de Ciências, quando se deparam com a missão de planejar, aplicar e avaliar estratégias didáticas que visam ensinar temas sobre a Ciência. A figura 1 resume o modelo.

\footnotetext{
${ }^{2}$ Para uma revisão sobre a temática do PCK, de forma geral, sugerimos uma consulta ao texto de Silva (2018). Já para uma revisão sobre o PCK/NdC, sugerimos uma consulta aos textos de Silva e Martins (2018; 2019).
} 


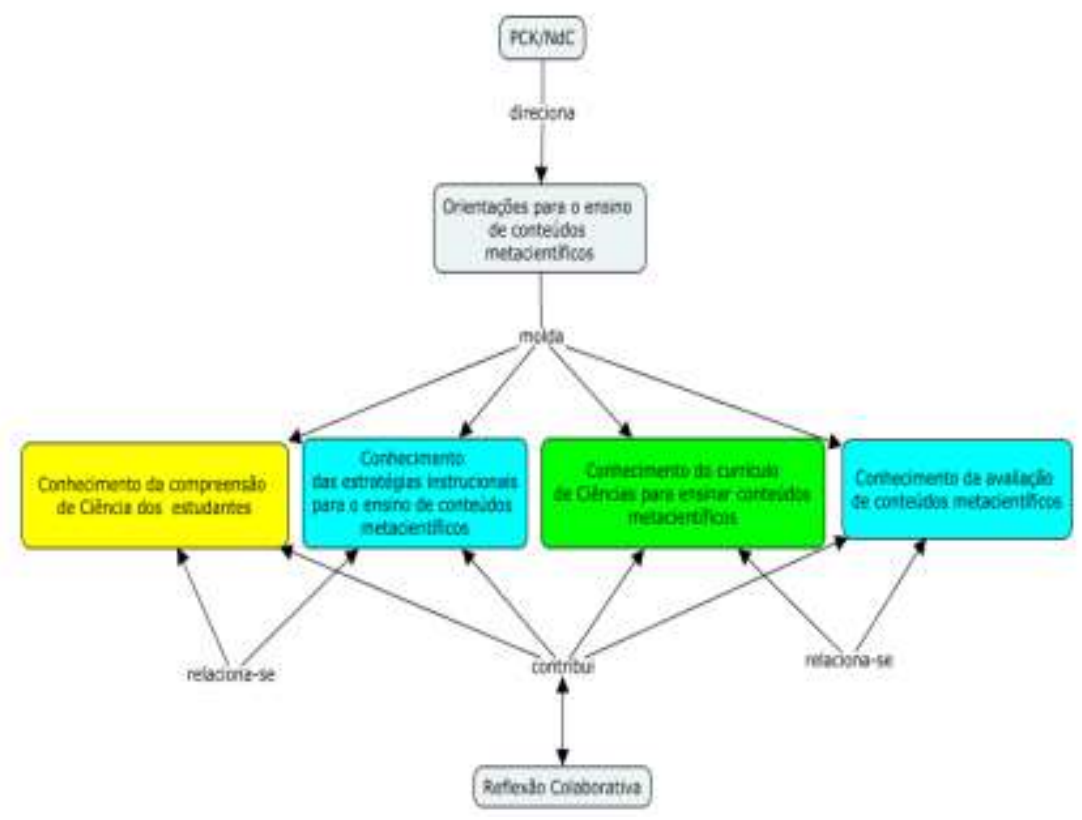

Figura 1 - Proposta de PCK/NdC de futuros professores de Física. Fonte: Silva e Martins (2019, p 742).

No quadro 1, apresentamos uma síntese do modelo de PCK/NdC dos autores, com base nos seus próprios trabalhos.

\begin{tabular}{|l|l|}
\hline \multicolumn{1}{|c|}{ Conhecimento relacionado ao PCK/NdC } & \multicolumn{1}{c|}{ Descrição sucinta } \\
\hline $\begin{array}{l}\text { Conhecimento da compreensão de Ciência dos } \\
\text { estudantes da Educação Básica }\end{array}$ & $\begin{array}{l}\text { Configuram-se como os conhecimentos dos } \\
\text { professores sobre a compreensão dos estudantes sobre } \\
\text { a Ciência, conhecimentos prévios e dificuldades de } \\
\text { aprendizagem relacionadas aos conhecimentos } \\
\text { metacientíficos. }\end{array}$ \\
\hline $\begin{array}{l}\text { Conhecimento das estratégias instrucionais para o } \\
\text { ensino de conteúdos metacientíficos }\end{array}$ & $\begin{array}{l}\text { Diz respeito ao conhecimento de estratégias didáticas } \\
\text { relacionadas aos conhecimentos metacientíficos, } \\
\text { principalmente suas potencialidades e dificuldades de } \\
\text { inserção. }\end{array}$ \\
\hline $\begin{array}{l}\text { Conhecimento do currículo de Ciências para ensinar } \\
\text { conteúdos metacientíficos }\end{array}$ & $\begin{array}{l}\text { Este componente compreende o conhecimento que os } \\
\text { professores necessitam possuir sobre as metas e } \\
\text { objetivos de aprendizagens dos alunos em relação aos } \\
\text { conhecimentos metacientíficos que desejam lecionar. }\end{array}$ \\
\hline $\begin{array}{l}\text { Conhecimento da avaliação de conteúdos } \\
\text { metacientíficos }\end{array}$ & $\begin{array}{l}\text { le avaliação das aprendizagens de conhecimentos } \\
\text { metacientíficos, que são aprendidos e vivenciados } \\
\text { pelos futuros professores de Física na sua formação } \\
\text { inicial. Nele, ele encontra exemplos o orientações de } \\
\text { propostas de avaliação específicas para a situação, } \\
\text { decorrentes, principalmente de experiências } \\
\text { formativas. }\end{array}$ \\
\hline
\end{tabular}

Quadro 1- Conhecimentos que compõem o PCK/NdC.

Fonte: Extraído de Silva e Martins $(2018 ; 2019)$.

O PCK/NdC configura-se como o conjunto de conhecimentos e suas representações didáticas que fundamentam a aprendizagem de aspectos da $\mathrm{NdC}$ pelos estudantes. 
Com base no exposto acima, e utilizando-se do referencial de PCK e PCK/NdC, neste trabalho buscamos desenvolver um estudo que possibilite compreender como se dá a mobilização do PCK/NdC, de uma futura professora de Ciências da Natureza, quando lhe é solicitado a construção de uma sequência didática que visa o ensino de temas sobre a Ciência, com destaque para a compreensão da imagem do cientista e, em especial, o papel da mulher na Ciência.

\section{O CORE COMO FERRAMENTA DE ACESSO AO PCK E PCK/NDC}

No tópico anterior apresentamos e discutimos brevemente sobre PCK e PCK/NdC, contudo cabe-nos questionar, como é possível acessar (mesmo que sejam indícios) a mobilização do PCK, de forma geral, e do PCK/NdC, de forma específica, de professores de Ciências, quando eles exercem suas atividades de planejamento, aplicação e avaliação de estratégias didáticas?

Como destaca Silva (2018), acessar o PCK (ou PCK/NdC, no caso do nosso estudo) não é uma tarefa trivial e nem muito menos simples. Na sua tese de doutorado, o pesquisador apresenta que nas investigações dessa natureza, a principal característica reside na pluralidade de instrumentos de coleta de dados, como, por exemplo, questionários, entrevistas e, principalmente, o estudo dos próprios materiais produzidos pelos docentes, sejam eles, por exemplo, textos, unidades didáticas, provas, planejamento ou sequências didáticas.

Contudo, como aponta, ainda, Silva (2018), o principal instrumento para acessar o PCK nas pesquisas ao redor do planeta é o questionário chamado Representação de Conteúdo (CoRe).

Ele foi proposto por Loughran, Mulhall e Berry (2004), que lançam uma proposta de capturar, documentar e retratar o conhecimento dos professores para o ensino através de uma lente do PCK, o qual eles intitularam de CoRe. Segundo os autores, a proposição do instrumento surgiu a partir de suas próprias investigações, nas quais apresentavam que os caminhos tradicionais dos estudos do PCK se tornavam inadequados, quando o objetivo é capturá-los com uso dos instrumentos usuais de pesquisas qualitativas.

Para os investigadores, o CoRe centra-se na compreensão do professor em relação aos aspectos do conteúdo específico. Ele apresenta oito questões relacionadas ao processo de ensino de conteúdos específicos. O instrumento, adaptado para esta pesquisa e respondido pela participante, pode ser visto, na íntegra, nos anexos. 
O CoRe é com frequência utilizado em pesquisas que pretendem acessar o PCK de professores. Aydin e Boz (2013), a partir do CoRe, examinam a natureza da integração entre componentes do PCK em dois professores de Química experientes.

Silva (2018) o utiliza para compreender o desenvolvimento do PCK/NdC de futuros professores de Física, quando são solicitados a construírem estratégias didáticas para o ensino de temas sobre a Ciência.

Além da finalidade de acessar elementos do PCK dos professores, o CoRe também apresenta uma característica de ensino na sua formação. Em alguns casos, ele vem sendo usado também para estimular uma reflexão sobre o processo de ensino e aprendizagem de conteúdos específicos de professores, possibilitando, também, o entendimento da complexa relação entre a pedagogia e o conteúdo através de processos da sala de aula.

Por exemplo, Nilsson e Loughran (2012), em um curso que durou um semestre, o PCK foi introduzido como um constructo acadêmico e ferramenta conceitual. O objetivo era que os resultados do CoRe possibilitassem o planejamento, avaliação e desenvolvimento dos conhecimentos profissionais de futuros professores de Ciências, dando suporte para o desenvolvimento de aprendizagens sobre o seu ensino, através do foco no desenvolvimento dos seus PCK.

Bertram e Loughran (2012) examinaram como o CoRe impactou na prática de professores de ciências. O estudo durou dois anos e teve como objetivo determinar como um grupo de professores de Ciências interpretam, usam e desenvolvem seus PCK e o impacto causado pelas ferramentas neste desenvolvimento.

No próximo tópico, iremos apresentar o percurso metodológico do nosso estudo.

\section{DESENHO DO ESTUDO DESENVOLVIDO}

No estudo, anteriormente, já víamos apresentando que uma das preocupações das investigações em torno das pesquisas que investigam como o ensino e aprendizagem de aspectos da natureza do conhecimento científico residem nos processos de construção de atividades destes temas em sala de aula e, em particular, como se estruturam os pensamentos dos professores nesse caminho.

Neste trabalho, em especial, buscamos indícios da mobilização do PCK/NdC, de uma professora de Ciências em formação, quando a mesma é incentivada para a construção de uma sequência didática que trate da concepção do cientista e o papel da mulher na Ciência com estudantes do ensino fundamental. 
Entendemos que o estudo configura-se como de natureza qualitativo, conforme destacam Marconi (2003) e Moreira (2011), o investigador encontra-se imerso no local pesquisado (o pesquisador era o professor da disciplina) os dados coletados são descritivos e existe a preocupação com o processo desenvolvido e não, somente, com o produto. Além disso, compreendemos que o estudo também se apresenta como interpretativo, pois segundo Moreira (2011), investigações dessa natureza centram-se na:

[...] interpretações dos significados atribuídos pelos sujeitos às suas ações em uma realidade socialmente construída, através de observação participativa, isto é, o pesquisador fica imerso no fenômeno de interesse. Os dados obtidos por meio dessa participação são de natureza qualitativa e analisados de forma correspondente (MOREIRA, 2011, p. 76).

O estudo foi feito com uma futura professora de Ciências, estudante de um curso de licenciatura em Ciências da Natureza, de uma instituição pública brasileira. No momento da pesquisa, no semestre de 2019.1, ela já tinha cursado a metade do curso, concluindo disciplinas de conteúdos científicos, nos campos da Física, Química e Biologia, disciplinas do núcleo pedagógico, como Didática Geral, e cursava disciplinas da área de Ensino de Ciências, como Instrumentação para o ensino de Ciências e História e Filosofia da Ciência no ensino de Ciência (disciplina na qual foi desenvolvida a pesquisa). Mesmo estando no curso de licenciatura, a participante apresentava pouca (ou quase nenhuma experiência docente) e não tinha feito nenhum estágio curricular obrigatório.

Sobre a construção da sequência didática (Anexo A), ela ocorreu dentro da disciplina História e Filosofia da Ciência no ensino de Ciências, no semestre de 2019.1, na qual a participante frequentava. A disciplina tinha por característica discutir elementos da Epistemologia da Ciência, usando autores com Karl Popper, Thomas Kuhn, Paul Feyerabend e Gaston Bachelard, buscando respostas para questões sobre o que é (ou não) Ciência; como uma teoria é desenvolvida e entra em processo de estagnação; o papel do cientista na sociedade; além de estudos de alguns episódios históricos e de personagens (ditos importantes) no campo das Ciências da Natureza, como, por exemplo, Isaac Newton, Madame Curie, Charles Darwin, Galileu Galilei, Antoine Lavoisier, dentre outros, acentuando-se questões relacionadas ao seu campo de trabalho e influências, tanto de cunho científica como extracientífica, no processo de construção de suas teorias. Por fim, a disciplina também buscava uma problematização de questões relacionadas às concepções de Ciência e do cientista de alunos da educação básica e como trabalhá-las na sala de aula. 
Dessa forma, o objetivo desse estudo desemboca na compreensão de como uma futura professora de Ciências da Natureza mobiliza o seu PCK/NdC, ao construir uma sequência didática, com finalidades de ensinar temas sobre a Ciência no ensino fundamental, em especial, a compreensão da imagem do cientista e o papel da mulher na Ciência.

Como instrumentos de coleta de dados foi usado a sequência didática (SD) da estudante, cedida pela mesma para investigação, como também o questionário Representação de Conteúdo (CoRe), encontrado no Anexo B. Os dois instrumentos tinham como função captar indícios da mobilização do $\mathrm{PCK} / \mathrm{NdC}$ da investigada no processo de construção da SD e, também, apontar potencialidades e deficiências da futura professora nesse processo de elaboração de uma estratégia didática com finalidade de trabalhar essa temática com alunos do ensino fundamental.

No processo de análise de dados, usamos como categorias gerais os conhecimentos que fazem parte do PCK/NdC propostos por Silva e Martins (2018; 2019), que são: Conhecimento da compreensão de Ciência dos estudantes da Educação Básica, conhecimento das estratégias instrucionais para o ensino de conteúdos metacientíficos, conhecimentos do currículo de Ciências para ensinar conteúdos metacientíficos e conhecimentos da avaliação de conteúdos metacientíficos.

\section{INDÍCIOS DA MOBILIZAÇÃO DO PCK/NDC NA SEQUÊNCIA DIDÁTICA}

Para analisar os dados, usamos como categorias os conhecimentos que fazem parte do PCK/NdC propostos por Silva e Martins (2018; 2019), conforme destacam acima. Começaremos pelo Conhecimento da compreensão de Ciência dos estudantes da educação básica, o qual perpassa pela compreensão de concepções prévias, dificuldades de aprendizagem e crenças sobre as possibilidades dos seus estudantes de aprenderem ou não sobre o conteúdo a ser discutido. Na SD da futura professora de Ciências notamos alguns elementos que indicam a presença desse conhecimento, observe:

\section{Desenvolvimento metodológico:}

$1^{\circ}$ Aula: Questionário e conteúdo.

Aplicação de um questionário para verificaçōes dos conhecimentos prévios dos alunos.

Discussões em tomo do conteúdo questionado, a fim de saber qual a opiniào dos alunos, em relaçăo à temática, analisando ainda o comportamento referente às opiniǒes contrarias das suas.

Duraçào: 60 minutos cada, total de 120 minutos.

Figura 2 - Excerto do desenvolvimento metodológico da SD. Fonte: Recorte da SD da participante.

Na figura 2, percebemos a preocupação da futura professora de iniciar a sua SD com um questionário para acessar as concepções dos estudantes sobre a Ciência, mostrando indícios da 
mobilização do conhecimento da compreensão de Ciência dos estudantes da educação básica. Em outros momentos da SD é possível notar a preocupação com a possível permanência de concepções não adequadas sobre a Ciência, como podemos perceber no planejamento das aulas 3 e 4.

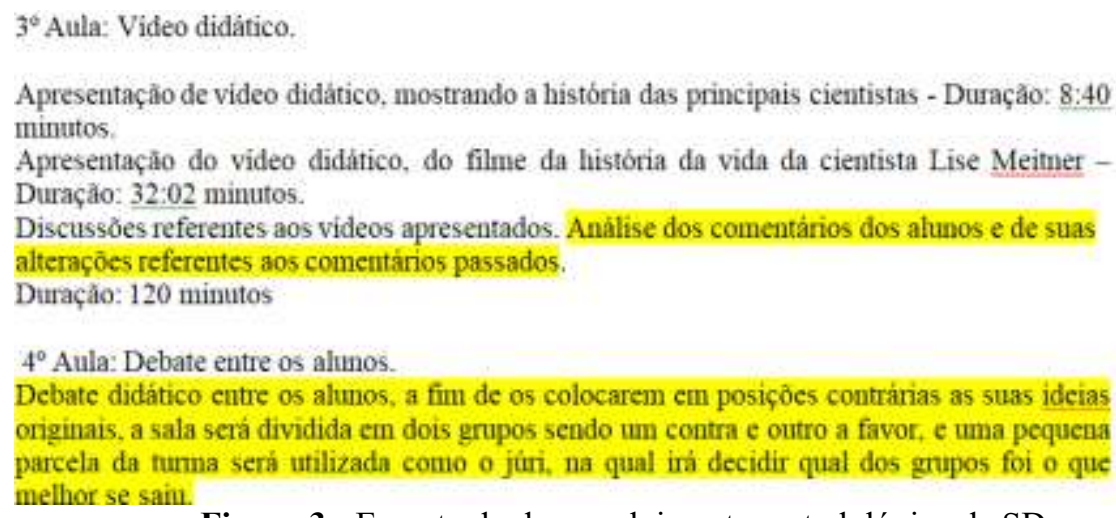

Figura 3 - Excerto do desenvolvimento metodológico da SD. Fonte: Recorte da SD da participante, grifo nosso.

No CoRe da participante é possível notar a preocupação em trabalhar essas compreensões inadequadas que seus futuros discentes possam apresentar. Ela também apresenta possíveis dificuldades de aprendizagem relacionadas aos conceitos impróprios que são transmitidos, geralmente, em filmes e programas de televisão.

Compreendam a história da Ciência no ponto de vista das mulheres, frisando a luta contra o preconceito e a busca pelos seus direitos. Conheçam novas perspectivas e a realidade de um cientista, a fim de mostrar que não é algo tão distante da realidade das pessoas comuns. Que as discussões nas aulas não influenciem pensamentos retrógrados a fim de expandir novos horizontes e romper preconceitos (CoRe, questão $1)$.

Pensamentos e preconceitos passados em geração, através de filmes e programas, ao não apoio da família em relação ao desenvolvimento da ideia de ser cientista (CoRe, questão 4).

Preconceitos e teorias embasadas em filmes e programas populares, com ideias atrasadas e não contextualizadas com a realidade de um cientista real (CoRe, questão $5)$.

A seguir, discutimos a influência dos conhecimentos relacionados ao campo das estratégias didáticas na mobilização do $\mathrm{PCK} / \mathrm{NdC}$ da futura professora. Ele retrata conhecimentos de estratégias didáticas relacionadas aos conhecimentos metacientíficos, principalmente suas potencialidades e dificuldades de inserção. Na SD da futura professora, podemos notar uma diversidade de estratégias didáticas, como podemos ver no quadro 2. 


\begin{tabular}{|c|l|c|}
\hline Aula & \multicolumn{1}{|c|}{ Atividade } & \multicolumn{1}{|c|}{ Tipo de atividade } \\
\hline 1 & $\begin{array}{l}\text { Aplicação de um questionário para verificações dos } \\
\text { conhecimentos prévios dos alunos. } \\
\text { Discussões em torno do conteúdo questionado, a fim } \\
\text { de saber qual a opinião dos alunos, em relação à } \\
\text { temática, analisando ainda o comportamento } \\
\text { referente às opiniões contrarias das suas. }\end{array}$ & Questionário e discussão em grupo \\
\hline 2 & $\begin{array}{l}\text { Iniciação do conteúdo (A história de grandes } \\
\text { pulheres na ciência) contemplando os principais } \\
\text { pilares e exemplos dentro da área, estimulando } \\
\text { sempre discussões com os alunos sobre a temática. }\end{array}$ & Aula expositiva e dialogada \\
\hline 3 & $\begin{array}{l}\text { Apresentação de vídeo didático, mostrando a } \\
\text { história das principais cientistas, com foco na vida } \\
\text { da cientista Lise Meitner. }\end{array}$ & $\begin{array}{l}\text { Debate didático entre os alunos, a fim de os } \\
\text { colocarem em posições contrarias as suas ideias } \\
\text { originais, a sala será dividida em dois grupos sendo } \\
\text { um contra e outro a favor da mulher na Ciência. }\end{array}$ \\
\hline 4
\end{tabular}

\section{Quadro 2- Atividades propostas na SD.}

Fonte: Extraído da SD da participante.

Notamos que esse conhecimento parece bem estruturado no PCK/NdC da participante. Ela consegue estruturar várias atividades para tratar da temática e apresenta lógica entre elas, possibilitando ao seu futuro discente que as suas ideias sejam sempre problematizadas em aulas futuras, proporcionando maiores possibilidades da construção de uma compreensão mais adequada do papel do cientista e da mulher na Ciência.

Abaixo, iniciaremos a discussão da influência dos conhecimentos relacionados no campo curricular na mobilização do $\mathrm{PCK} / \mathrm{NdC}$ da participante. Ele diz respeito sobre as metas e objetivos de aprendizagens dos alunos em relação aos conhecimentos metacientíficos que desejam lecionar, envolvendo as relações dos objetivos e conteúdos e o conhecimento de documentos oficiais da área.

Na SD da participante podemos notar que os objetivos e conteúdos estão bem traçados para uma discussão sobre o papel da mulher na Ciência, apresentando coerência com a metodologia que foi idealizada para tal finalidade. Veja figura 4. 
Objetivos especificos:

1. Compreender a história da Ciência, no ponto de vista das mulheres, frisando a luta contra o preconceito e a busca pelos seus direitos.

2. Apresentar novas perspectivas e a realidade de um cientista, a fim de mostrar que nào é algo tão distante da realidade das pessoas comuns.

3. Influenciar pensamentos não retrógrados a fim de expandir novos horizontes e romper preconceitos.

1.0- Conteúdos: A história da Ciência

1.1 - O ser cientista

2.0 - A história de grandes mulheres na ciência

3.0- Como é um trabalho cientifico

Figura 4 - Excerto do desenvolvimento metodológico da SD.

Fonte: Recorte da SD da participante.

Os objetivos da SD são reforçados no CoRe da participante, especialmente nas respostas

1 e 2.

Compreendam a história da Ciência no ponto de vista das mulheres, frisando a luta contra o preconceito e a busca pelos seus direitos. Conheçam novas perspectivas e a realidade de um cientista, a fim de mostrar que não é algo tão distante da realidade das pessoas comuns. Que as discussões nas aulas não influenciem pensamentos retrógrados a fim de expandir novos horizontes e romper preconceitos (CoRe, questão $1)$.

Para desenvolver novos pontos de vista, dentro de um assunto que não é tão comentado no meio familiar e escolar, frisando atualizar e conhecer a nova realidade das mulheres e dos cientistas (CoRe, questão 2).

Por fim, teceremos as considerações sobre a influência dos conhecimentos da avaliação na mobilização do PCK/NdC da participante. Esse componente do PCK/NdC, com base na SD e no CoRe da investigada. Ela destaca que a avaliação será feita por intermédio de questionários e debates, mas não esclarece o que deseja observar nestas atividades, não fazendo relações com os conteúdos propostos na SD. Parece-nos que foi pouco desenvolvido na base de ensino da futura professora, o que acarretou a mínima percepção de como será feita a aprendizagem dos seus estudantes sobre o papel da mulher da Ciência.

No próximo tópico, apresentamos as conclusões desse estudo.

\section{CONCLUSÕES DO ESTUDO}

Neste estudo relatamos a presença de indícios da mobilização do $\mathrm{PCK} / \mathrm{NdC}$ de uma futura professora de Ciência quando é solicitada a construção de uma sequência didática com o objetivo de discutir o papel da mulher na Ciência.

Inicialmente, o estudo serviu para a percepção que a união da produção e avaliação de SD's, juntamente com a resolução do CoRe, apresentam-se como ferramentas úteis para o acesso do PCK/NdC, que, segundo Silva e Martins (2018; 2019), é bastante complicado, pois 
a sua natureza instável possibilita transformações de conhecimentos que o compõe, a partir de novas experiências didáticas.

Segundo, evidenciamos que no processo de construção da SD, os diferentes conhecimentos que compõe o PCK/NdC são acessados para a tarefa, o que denota que ela pode se tornar como uma ferramenta interessante tanto para a detecção do PCK/NdC como para a percepção de elementos da formação de futuros docentes que potencializam ou tornam-se obstáculos para o desenvolvimento do $\mathrm{PCK} / \mathrm{NdC}$.

No que tange aos elementos potencializadores, notamos que os conhecimentos referentes às estratégias didáticas apresentaram-se bem desenvolvidos na futura professora, o que pode possibilita uma discussão mais aprofundada, diante de seus futuros discentes, do papel da mulher na Ciência, foco da SD produzida.

Outro ponto positivo, que vale destacar nesse estudo, diz respeito à preocupação tanto em acessar as concepções dos discentes sobre o papel da mulher na Ciência como em problematizá-lo no decorrer de toda a SD. Esse fato pode denotar o desenvolvimento de conhecimentos referentes à compreensão da Ciência e como discuti-lo com seus alunos no seu PCK/NdC. Entretanto, nessa investigação, não temos elementos para caracterizar se estes elementos do PCK/NdC foram desenvolvidos nas aulas de História e Filosofia da Ciência ou em outras disciplinas, ou até mesmo, em diferentes espaços formativos que a futura professora frequentou na sua formação.

Um ponto que percebemos que pode dificultar o desenvolvimento do $\mathrm{PCK} / \mathrm{NdC} \mathrm{diz}$ respeito aos conhecimentos referentes à avaliação de temas sobre a NdC. Na SD da participante notamos que ela apresentou dificuldades em elaborar ferramentas avaliativas para a sua proposta. Esse ponto também é abordado na pesquisa de Silva e Martins (2019), que salientam que professores com pouca experiência apresentam dificuldades em avaliar aspectos sobre a $\mathrm{NdC}$, perfil bastante parecido da nossa participante.

Por fim, sugerimos aos docentes formadores que a proposição de atividades que potencializem o $\mathrm{PCK} / \mathrm{NdC}$ de futuros professores de Ciências pode colaborar no desenvolvimento da base de ensino destes docentes, favorecendo a detecção de elementos que potencializam e contribuem nesse sentido. 


\section{AGRADECIMENTOS}

O autor agradece a estudante do curso de licenciatura em Ciências da Natureza que autorizou o uso da sua SD e do CoRe, feitos na disciplina de História e Filosofia da Ciência, como ferramentas para a construção deste estudo.

\section{REFERÊNCIAS}

AYDIN, S.; BOZ, Y. The nature of integration among PCK components: A case study of two experienced chemistry teachers. Chemistry Education Research and Practice, v. 14, n. 4, p. 615-624, 2013. ISSN: 17561108. Disponível em:

https://pubs.rsc.org/en/content/articlelanding/2013/rp/c3rp00095h\#!divAbstract. Acesso: 07 jan 2019. Doi: https://doi.org/10.1039/C3RP00095H.

BERTRAM, A; LOUGHRAN, J. Science teachers' views on CoRes and PaP-eRs as a framework for articulating and developing pedagogical content knowledge. Research in Science Education, v. 42, n. 6, p. 1027-1047, 2012. ISSN: 15731898. Disponível em: https://link.springer.com/article/10.1007\%2Fs11165-011-9227-4 Acesso em 10 jan 2019. Doi: https://doi.org/10.1007/s11165-011-9227-4.

DEMIRDOGEN, B.; HANUSCIN, D. L.; UZUNTIRYAKI-KONDAKCI, E.; KOSEOGLU, F. Development and nature of preservice chemistry teachers' pedagogical content knowledge for nature of science. Research in Science Education, p. 1-38, 2015. ISSN: 15731898. Disponível em: https://link.springer.com/article/10.1007/s11165-015-9472-z. Acesso: 05 jan 2020. Doi: https://doi.org/10.1007/s11165-015-9472-z

GESS-NEWSOME, J. Pedagogical content knowledge: An introduction and orientation. In: GESS-NWESOME, J.; LEDERMAN, N.G. (Eds). Examining pedagogical content knowledge: PCK and science education. Netherlands: Kluwer Academic Publisher, 1999. p. 3-17.

HANUSCIN, D. L.; LEE, M. H.; AKERSON, V. L. Elementary teachers' pedagogical content knowledge for teaching the nature of science. Science Teacher Education, v. 95, n. 1, p. 145-167, 2010. ISSN: 1098237X. Disponível em: https://onlinelibrary.wiley.com/doi/full/10.1002/sce.20404. Acesso: 03 jan 2020. Doi: https://doi.org/10.1002/sce.20404.

KIND, V. Pedagogical content knowledge in science education: perspectives and potential for progress. Studies in Science Education, v. 45, n. 2, p. 169-204, 2009. ISSN: 19408412. Disponível em: https://www.tandfonline.com/doi/abs/10.1080/03057260903142285. Acesso em: 07 jan 2020. Doi: https://doi.org/10.1080/03057260903142285.

LOUGHRAN, J.; MULHALL, P.; BERRY, A. In search of pedagogical content knowledge in science: Developing ways of articulating and documenting professional practice. Journal of research in science teaching, v. 41, n. 4, p. 370-391, 2004. ISSN: Disponível em: https://onlinelibrary.wiley.com/doi/abs/10.1002/tea.20007. Acesso em: 02 jan 2020. Doi: https://doi.org/10.1002/tea.20007. 
MAGNUSSON, S.; KRAJCIK, J.; BORKO, H. Nature, sources, and development of pedagogical content knowledge for science teaching. In: Examining pedagogical content knowledge. Springer Netherlands, 1999. p. 95-132.

MARCONI, M.A. Fundamentos de metodologia científica. São Paulo: Atlas, 2003.

MOREIRA, M.A. Metodologia de Pesquisa em Ensino. São Paulo: Livraria da Física, 2011.

NILSSON, P.; LOUGHRAN, J. Exploring the development of pre-service science elementary teachers' pedagogical content knowledge. Journal of Science Teacher Education, v. 23, n. 7, p. 699-721, 2012. ISSN: Disponível em:

https://link.springer.com/article/10.1007\%2Fs10972-011-9239-y. Acesso em: 02 jan 2020. Doi: https://doi.org/10.1007/s10972-011-9239-y.

SCHWARTZ, R. S.; LEDERMAN, N. G. "It's the nature of the beast": The influence of knowledge and intentions on learning and teaching nature of science. Journal of Research in Science Teaching, v. 39, n. 3, p. 205-236, 2002. ISSN: 10982736. Disponível em: https://onlinelibrary.wiley.com/doi/abs/10.1002/tea.10021. Acesso em: 03 fev 2020. Doi: https://doi.org/10.1002/tea.10021.

SHULMAN, L. S. Knowledge and teaching: Foundations of the new reform. Harvard Education Review, v. 57, n. 1, p. 1-23, 1987. ISSN 1943-5045. Disponível em: https://hepgjournals.org/doi/pdf/10.17763/haer.57.1.j463w79r56455411. Acesso em: 05 jan 2017. Doi: https://doi.org/10.17763/haer.57.1.j463w79r56455411.

SHULMAN, L. S. Those who understand: Knowledge growth in teaching. Educational Researcher, p. 4-14, 1986. ISSN: 1935-102X. Disponível em: https://journals.sagepub.com/doi/pdf/10.3102/0013189X015002004. Acesso em: 05 jan. 2017. Doi: https://doi.org/10.3102/0013189X015002004.

SILVA, B. V. C. O desenvolvimento do conhecimento pedagógico do conjunto referente à temática Natureza da Ciência na formação inicial de professores de Física. 2018. $302 \mathrm{f}$. Tese (Doutorado) - Universidade Federal do Rio Grande do Norte, Programa de PósGraduação em Ensino de Ciências e Matemática, Natal, 2018.

SILVA, B. V. C.; MARTINS, A. F. P. Uma proposta para avaliação do desenvolvimento do conhecimento pedagógico do conteúdo de futuros professores de Física acerca da temática Natureza da Ciência. Caderno Brasileiro de Ensino de Física, Florianópolis, v. 35, n. 2, p. 389-413, set. 2018. ISSN 2175-7941. Disponível em:

<https://periodicos.ufsc.br/index.php/fisica/article/view/2175-7941.2018v35n2p389>. Acesso em: 02 jan. 2020. DOI: https://doi.org/10.5007/2175-7941.2018v35n2p389.

SILVA, B. V. C.; MARTINS, A. F. P. O conhecimento pedagógico do conteúdo referente ao tema Natureza da Ciência na formação inicial de professores de Física. Caderno Brasileiro de Ensino de Física, Florianópolis, v. 36, n. 3, p. 735-768, dez. 2019. ISSN 2175-7941. Disponível em: <https://periodicos.ufsc.br/index.php/fisica/article/view/21757941.2019v36n3p735>. Acesso em: 02 jan. 2020. DOI: https://doi.org/10.5007/21757941.2019v36n3p735. 
Submetido em: 02 de junho de 2020.

Aprovado em: 13 de outubro de 2020.

\section{Anexos}

Anexo A: Sequência didática produzida pela professora

\begin{tabular}{|c|c|c|}
\hline \multicolumn{3}{|c|}{$\begin{array}{l}\text { Escola: REMOVIDO } \\
\text { Professor (a): REMOVID }\end{array}$} \\
\hline $\begin{array}{l}\text { Disciplina: Ciências } \\
\text { Série: } 7^{\circ} \text { ano }\end{array}$ & $\begin{array}{l}\text { Data: } \\
04 / 02 / 2020 \text { à } \\
25 / 02 / 2020\end{array}$ & $\begin{array}{l}\text { Duração: Duas horas por aula, totalizando } 10 \\
\text { horas/aula }\end{array}$ \\
\hline \multicolumn{3}{|c|}{$\begin{array}{l}\text { Objetivos específicos: } \\
\text { 1. Compreender a história da Ciência, no ponto de vista das mulheres, frisando a luta contra o preconceito } \\
\text { e a busca pelos seus direitos. } \\
\text { 2. Apresentar novas perspectivas e a realidade de um cientista, a fim de mostrar que não é algo tão } \\
\text { distante da realidade das pessoas comuns. } \\
\text { 3. Influenciar pensamentos não retrógrados a fim de expandir novos horizontes e romper preconceitos. }\end{array}$} \\
\hline \multicolumn{3}{|c|}{$\begin{array}{l}1.0 \text { - Conteúdos: A história da Ciência } \\
1.1 \text { - O ser cientista } \\
2.0 \text { - A história de grandes mulheres na ciência } \\
3.0 \text { - Como é um trabalho cientifico }\end{array}$} \\
\hline \multicolumn{3}{|c|}{ Desenvolvimento metodológico: } \\
\hline \multicolumn{3}{|c|}{$\begin{array}{l}\text { Aplicação de um questionário para verificações dos conhecimentos prévios dos alunos. } \\
\text { Discussões em torno do conteúdo questionado, a fim de saber qual a opinião dos alunos, em relação à } \\
\text { temática, analisando ainda o comportamento referente às opiniões contrarias das suas. } \\
\text { Duração: } 60 \text { minutos cada, total de } 120 \text { minutos. }\end{array}$} \\
\hline \multicolumn{3}{|c|}{$2^{\circ}$ Aula: Conteúdo, 2.0 - A história de grandes mulheres na ciência } \\
\hline \multicolumn{3}{|c|}{$\begin{array}{l}\text { Iniciação do conteúdo contemplando os principais pilares e exemplos dentro da área, estimulando } \\
\text { sempre discussões com os alunos sobre a temática. } \\
\text { Duração: } 120 \text { minutos. }\end{array}$} \\
\hline \multicolumn{3}{|c|}{$3^{\circ}$ Aula: Vídeo didático. } \\
\hline \multicolumn{3}{|c|}{$\begin{array}{l}\text { Apresentação de vídeo didático, mostrando a história das principais cientistas - Duração: 8:40 minutos. } \\
\text { Apresentação do vídeo didático, do filme da história da vida da cientista Lise Meitner - Duração: 32:02 } \\
\text { minutos. }\end{array}$} \\
\hline \multicolumn{3}{|c|}{$\begin{array}{l}\text { Discussões referentes aos vídeos apresentados. Análise dos comentários dos alunos e de suas alterações } \\
\text { referentes aos comentários passados. } \\
\text { Duração: } 120 \text { minutos }\end{array}$} \\
\hline \multicolumn{3}{|c|}{$4^{\circ}$ Aula: Debate entre os alunos. } \\
\hline \multicolumn{3}{|c|}{$\begin{array}{l}\text { Debate didático entre os alunos, a fim de os colocarem em posições contrarias as suas ideias originais, } \\
\text { a sala será dividida em dois grupos sendo um contra e outro a favor, e uma pequena parcela da turma } \\
\text { será utilizada como o júri, na qual irá decidir qual dos grupos foi o que melhor se saiu. } \\
\text { - } \quad \text { Cada grupo terá } 15 \text { minutos para criar uma tese a favor de seu tema. } \\
\text { - } \quad \text { Cada grupo terá } 15 \text { minutos para apresentar seu tema, e exemplificar. } \\
\text { - Cada grupo terá um lance de } 5 \text { perguntas para o oponente, no qual deve ser retrucada. } \\
\text { E por fim, o júri terá } 15 \text { minutos para decidir qual o melhor grupo, e em seguida mais } 10 \text { minutos para } \\
\text { apresentar o porquê do seu posicionamento. } \\
\text { Duração: } 120 \text { minutos. }\end{array}$} \\
\hline
\end{tabular}


$5^{\circ}$ Aula: Segundo debate entre os alunos, trocando os grupos.

Debate didático entre os alunos, a fim de os colocarem em posições contrarias as suas ideias originais, a sala será dividida em dois grupos sendo um contra e outro a favor, e uma pequena parcela da turma será utilizada como o júri, na qual irá decidir qual dos grupos foi o que melhor se saiu.

Dessa vez, os grupos formados originalmente na aula anterior deveram se manter porém, dessa vez terem um posicionamento contrário.

Cada grupo terá 10 minutos para criar uma tese a favor de seu tema.

Cada grupo terá 10 minutos para apresentar seu tema, e exemplificar.

Cada grupo terá um lance de 5 perguntas para o oponente, no qual deve ser retrucada.

E por fim, o júri terá 10 minutos para decidir qual o melhor grupo, e em seguida mais 10 minutos para apresentar o porquê do seu posicionamento.

Será dado como atividade para casa um questionário referente aos vídeos das aulas anterior, e referente aos debates.

Duração: 120 minutos.

Recursos Didáticos:

Sala de aula com: Quadro branco, pincel, apagador e data show.

Materiais de aulas: Notebook, celular, materiais recicláveis como papeis, laser.

Avaliação: As avaliações serão:

Qualitativas: Acompanhamento da participação das discussões e debates em sala de aula

Quantitativa: Resolução de questionários abertos e fechados respectivos a cada aula ministrada

Referências dos vídeos:

https://www.youtube.com/watch?v=WWvIQJg4SCM

https://www.youtube.com/watch?v=U2yTT8cWYoU

\section{Anexo B: Questionário - Representação de Conteúdo, com respostas da participante}

\begin{tabular}{|c|l|}
\hline Questões do Core & \multicolumn{1}{c|}{ Ideia } \\
\hline $\begin{array}{c}\text { 1. O que você pretende que os } \\
\text { estudantes aprendam sobre essa ideia? }\end{array}$ & $\begin{array}{l}\text { Compreendam a história da Ciência no ponto de vista das } \\
\text { mulheres, frisando a luta contra o preconceito e a busca pelos } \\
\text { seus direitos. } \\
\text { Conheçam novas perspectivas e a realidade de um cientista, a } \\
\text { fim de mostrar que não é algo tão distante da realidade das } \\
\text { pessoas comuns. } \\
\text { Que as discussões nas aulas não influenciem pensamentos } \\
\text { retrógrados a fim de expandir novos horizontes e romper } \\
\text { preconceitos. }\end{array}$ \\
\hline $\begin{array}{c}\text { 2. Por que é importante para o } \\
\text { estudante aprender essa ideia? }\end{array}$ & $\begin{array}{l}\text { Para desenvolver novos pontos de vista, dentro de um assunto } \\
\text { que não é tão comentado no meio familiar e escolar, frisando } \\
\text { atualizar e conhecer a nova realidade das mulheres e dos } \\
\text { cientistas. }\end{array}$ \\
\hline $\begin{array}{c}\text { 3. O que você sabe a mais sobre essa } \\
\text { ideia? }\end{array}$ & $\begin{array}{l}\text { O reconhecimento de "brincadeiras" sexistas que não são } \\
\text { percebidas como preconceito, e situações explícitas de } \\
\text { preconceito de gênero. E à necessidade de conciliar a profissão } \\
\text { com as responsabilidades familiares, que implicou jornadas } \\
\text { parciais de trabalho, o adiamento ou recusa da maternidade. }\end{array}$ \\
\hline $\begin{array}{c}\text { 4. Quais são as dificuldade e } \\
\text { limitações ligadas ao ensino dessa } \\
\text { ideia? }\end{array}$ & $\begin{array}{l}\text { Pensamentos e preconceitos passados em geração, através de } \\
\text { filmes e programas, ao não apoio da família em relação ao } \\
\text { desenvolvimento da ideia de ser cientista. }\end{array}$ \\
\hline
\end{tabular}




\begin{tabular}{|c|l|}
\hline $\begin{array}{c}\text { 5. Que conhecimento sobre o } \\
\text { pensamento dos estudantes tem } \\
\text { influência no seu ensino sobre essa } \\
\text { ideia? }\end{array}$ & $\begin{array}{l}\text { Preconceitos e teorias embasadas em filmes e programas } \\
\text { populares, com ideias atrasadas e não contextualizadas com a } \\
\text { realidade de um cientista real. }\end{array}$ \\
\hline $\begin{array}{c}\text { 6. Que outros fatores influenciam no } \\
\text { ensino desta ideia? }\end{array}$ & A falta de apoio dos familiares na ideia do ser cientista. \\
\hline $\begin{array}{c}\text { 7. Que procedimentos/estratégias } \\
\text { você emprega para que os alunos se } \\
\text { comprometam com essa ideia? }\end{array}$ & $\begin{array}{l}\text { Aulas didáticas que apresentem a real realidade, atividades } \\
\text { comuns que cientistas empregam dentro de sua carreira, e } \\
\text { exemplificações de pessoas com histórias inspiradoras e reais. }\end{array}$ \\
\hline $\begin{array}{c}\text { 8. Que maneiras específicas você } \\
\text { utiliza para avaliar a compreensão dos } \\
\text { alunos sobre essa ideia? }\end{array}$ & $\begin{array}{l}\text { Avaliando com questionários, e debates que os coloquem de } \\
\text { frente com questões relacionadas. }\end{array}$ \\
\hline
\end{tabular}

